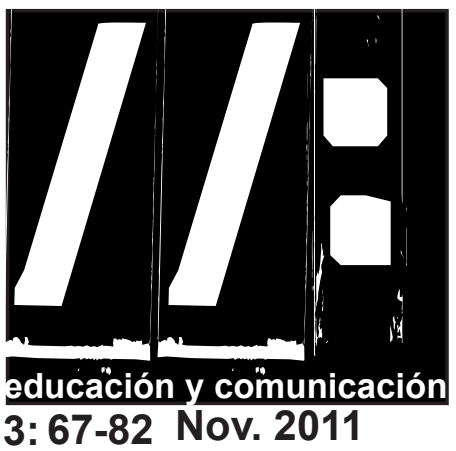

\title{
LA HOMOSEXUALIDAD EN EL GINE ÁRABE
}

\section{Homosexuality in Arabic Ginema}

\author{
Mohamed Lemrini El Ouahhabi \\ Doctor y profesor de comunicación de la \\ Universidad Europea de Madrid (España) \\ E-mial: mohammad.lemrini@gmail.com
}

Resumen: El tema de la homosexualidad ha sido un tabú entre los árabes, pero el cine, en diferentes ocasiones y en distintos países, lo ha recogido como argumento específico y lo ha planteado como algo secundario, del mismo modo que ha incluido imágenes de desnudos ante el apoyo de los colectivos más liberales, el rechazo del conservadorismo impuesto por los estamentos religiosos y el férreo control de la censura. Encontraremos que también se sale del armario y se interpretan, en infinidad de películas, inimaginables escenas con homosexuales de ambos sexos. La mayoría de estas películas son egipcias, pero también destacan algunos cineastas de Marruecos y Líbano y, sobre todo, el genial alejandrino Youssef Chahin.

Palabras clave: Cine, árabe, homosexualidad, censura.

Summary: Homosexuality has always been taboo in Arab culture, however, diverse Arabic countries have included this theme within their cinematic productions. Homosexuality may be projected within the plot or subplot, with the use of full nude scenes; a practice that liberal sectors of Arabic societies support, while the conservative religious wing attempt to control through censorships. Despite these attempts to curtail these themes, we can find numerous homosexual scenes involving both gay men and women in a number of Arabic films. The majority of these films are Egyptian, although we can also find filmmakers from Morocco and Libya, above all the genial Youssef Chahin. Key words: Cinema, Arabic, Homosexuality, censorship.

Recibido: 27-07-2011 / Revisado: 11-08-2011 / Aceptado: 19-08-2011 / Publicado: 30-10-2011

https://dx.doi.org/10.25267/Hachetetepe.2011.v2.i3.7 


\section{Introducción}

Cuando hablamos de cine árabe, indudablemente nos referimos al cine egipcio que ha rivalizado durante décadas las producciones norteamericana e india exhibidas en las diferentes salas árabes, desde Casablanca, hasta más allá de los confines de Bagdad, en el extremo oriental de Irak.

El cine llegó a Egipto una semana después de su debut aquel 28 de febrero de 1895 de mano de los Hermanos Lumière, para ser estrenado en el Café Zawani de Alejandría a primeros de enero de 1896 y el 28 del mismo mes en el local que se convertiría más adelante en el Cine Santi de El Cairo (1), que fue desde primeros del siglo XX el centro de creación artística de referencia para todo el mundo árabe.

A partir de entonces y siguiendo el desarrollo normal que ha conocido el nuevo arte en todo el mundo, Egipto comenzó a inundar a toda la comunidad árabe con sus producciones que, aunque pasadas por la censura local, conseguían interesar a una extensa población, calculada hoy día en alrededor de quinientos millones, que aplaudían a los astros de los "Estudios Egipto", imponiendo su habla, sus costumbres y su conservadurismo. Mientras tanto y poco a poco, el resto de países del mundo árabe comenzó a ver en sus calles, zocos y mercados a los enviados de Pathé, Lumière, etc. filmar imágenes exóticas que serían exhibidas en las salas de las capitales europeas.

En Egipto, después de la producción de varios cortometrajes y reportajes, se estrena el 16 de febrero de 1927 "Laila", el primer largometraje de ficción, con producción e interpretación de la legendaria actriz teatral Aziza Amir y la participación de varios amantes del nuevo arte, algunos de los cuales pasaron largas temporadas en Alemania para aprender el lenguaje del nuevo arte.

El cine egipcio que ha sorteado todas las dificultades, atendiendo a las vicisitudes de cada época, gobierno o transición, ha estado dominado por una mayoría burguesa y burócrata de cineastas que imponían su criterio comercial y chabacano, obstaculizando la participación de nuevos talentos cinematográficos, interesados en producir películas más ajustadas a la realidad social, política y económica, más acorde a las aspiraciones de los millones de espectadores de todo el mundo árabe, lo que ha llevado a varios directores a emigrar a otros países para producir sus obras: Tawfiq Saleh a Siria para rodar "Al majduun" (Los engañados) y el legendario Youssef Chahin a Argelia donde encuentra financiación para dirigir "Al osfour” (El gorrión), obra cumbre del cine árabe. Los demás países, y de una manera escalonada, conocen a partir de entonces el nacimiento de sus propias cinematografías.

\section{La homosexualidad en el mundo árabe}

La homosexualidad entre los devotos musulmanes es tenida como un pecado contra el orden establecido por Allah. La charia o ley islámica se dice que la condena firmemente y prescribe un severo castigo por su práctica, hasta el punto de que en Arabia Saudita se castiga con la muerte por lapidación. En otros países la condena puede llegar hasta diez años de prisión.

Pero vayamos por partes. En el Corán se producen ocho menciones al pueblo de Lot (2) considerado como transgresor por "entregarse a los hombres en concupiscencia prescindiendo de las mujeres" (3). En la Aleya 27:55-57 (4) se puede también leer: "Recuerda cuando Lot dijo a sus gentes: “Cometéis la 


\section{I/: La homosexualidad en el cine árabe}

\section{Monográfico}

torpeza mientras vosotros sois clarividentes? ¿Prescindiendo de las mujeres, os dirigís, concupiscentes, a los hombres? !Vosotros sois gentes que ignoráis!". La respuesta de sus gentes no consistió más que en decir: "!Expulsad a la familia de Lot de vuestra ciudad! ¡Ellos son individuos que se las dan de puros!”.

Realmente esto es lo más prohibitivo que se puede encontrar en El Corán. En los hadices, hechos y dichos atribuidos a Mahoma, existe una gran controversia sobre la autenticidad de los mismos y la condena que se dice que se debe imponer a los infractores hasta el punto de que algunos ulemas llegan a comparar la homosexualidad con el adulterio. Tarmadi cuenta que Mahoma dijo: "Maldito sea el que hace como la gente de Lot" y Ahmed narra que comentó "A quien encontréis haciendo lo mismo que la gente de Lot, matad al hacedor y al benefactor" (5). En todo caso, la división surge entre los primeros mandatarios musulmanes sobre cómo se debe matar a estas dos personas y cómo aplicar el castigo.

Pero la sociedad civil en todo el mundo árabe no es ajena a este hecho y, en la mayoría de los casos, se pretende incluso ignorar totalmente la existencia de la homosexualidad, que en árabe recibe el nombre de mazalia. En la sociedad árabe esta homosexualidad es considerada como un tema tabú, una aberración que nos ha llegado de la civilización Occidental, cuando realmente la historia y la literatura árabe están llenas de ejemplos donde no solo se habla de ello, sino que también se elogia por lo que se puede asegurar que los árabes han conocido este hecho desde la antigüedad. Lo más conocido, el famoso poeta arabo-iraní Abu Nawas que, de vida libertina y con mucha afición al vino, cantó al placer homosexual en el siglo VIII en estrofas como estas:
"He dejado las chicas por los muchachos Y por el vino viejo he dejado el agua clara" (6) En la actualidad, entre los países árabes la homosexualidad es prohibida de una manera legal en casi todos a excepción de Egipto, Irak, Jordania y Palestina, utilizándose en los tres primeros países diversas artimañas para castigar y perseguir a los homosexuales (aplicándose la ley contra la prostitución en Egipto, asesinatos cometidos por los escuadrones de la muerte en Irak o siendo víctimas de violencia en general en Jordania). La menor pena de prisión se aplica en Líbano (un año) y en Argelia (hasta dos años). En Marruecos, Omán, Siria, Somalia y Túnez la pena llega a tres años; cinco en Libia, siete en Kuwait y Qatar y hasta diez años en Bahréin. La pena de muerte por lapidación se aplica en Arabia Saudita y en Mauritania donde solo es para los hombres; y se aplica la pena de muerte también en los Emiratos Árabes, Sudán y Yemen, siendo en exclusividad para los hombres en los dos últimos países (7).

La Organización Mundial de la Salud no ha retirado la homosexualidad del manual de diagnóstico de enfermedades mentales hasta 1985. En los diferentes países del mundo, la homosexualidad ha ido presentándose como cosa normal y natural, siendo el colectivo de gays, lesbianas, transexuales y bisexuales apoyado por los estamentos internacionales y las asociaciones de defensa de los Derechos Humanos en todos los países. Del mismo modo, varios acontecimientos ensombrecieron el panorama de actualidad en las sociedades árabes al protagonizar y ocupar los grupos de homosexuales las primeras páginas de la prensa de sus respectivos países: el apoyo de un centenar de asociaciones de los sectores de Salud y de Derechos Humanos a nivel internacional a cinco homosexuales egipcios 
que el Palacio de Justicia del Nilo había condenado a cinco años de prisión en 2008 y la protesta mundial producida en 2009 por la condena de 67 hombres por vestir ropa femenina en una fiesta en Arabia Saudita, son los ejemplos más clásicos.

La manera en que se manifiesta el colectivo es diferente en cada país. Se reúnen en gimnasios, baños turcos, salones de masaje, cafeterías, discotecas, plazas y calles públicas o en fiestas privadas y/o públicas organizadas en zonas turísticas. Destacan y son distinguidos por su vestimenta: ropa muy estrecha y colores muy llamativos. Normalmente son provocadores a través de sus dichos o hechos, solo para confirmar su identidad y hacer constar que son seres humanos, que están allí y que la sociedad les debe por lo menos respeto.

La comunicación, los medios y la tecnología han estado a su favor y han permitido que haya una fluidez extraordinaria en la circulación de la información que les atañe. Internet y las redes sociales han permitido últimamente que se desarrollen y se difundan más todas las actividades que tienen que ver con ellos. Pero el tratamiento que se le otorga al homosexual, de cualquiera de las categorías (gay, lesbiana, transexual o bisexual), en el lenguaje escrito es denigrante, insultante y degradante. En vez de hablar de homosexualidad, se habla de aberración, desviación, perversión, excentricidad y extravagancia sexual.

Cada vez abundan más los artículos con una visión contraria a la difusión de la actividad homosexual. El doctor Nahi Cartagi llega incluso a afirmar que "son varios los factores internos que ayudan a la difusión de la degeneración moral de un modo general y de la aberración sexual particularmente. El principal de estos factores reside en la familia donde es criado el niño, que participa de un modo esencial en la formación de su personalidad y en dirigir su comportamiento. Y la mala educación que vemos en algunas familias comienza en la niñez y juega un papel importante en la aceptación en el futuro de su sexo varón sea o hembra. Entre estas actuaciones encontramos el dejar que a los niños lleven melenas, el permitirles jugar con juegos de niñas, vestirles con ropas de niñas, llamarlos con nombres de niñas, y el permitirles a ellas jugar con ellos a juegos que a veces son violentos" (8).

El escritor marroquí Abdulá Tayę ha sido el primer intelectual marroquí que ha difundido su homosexualidad en una "sociedad hipócrita" que impone la "ley del silencio" sobre un tema que está muy a la orden del día y que a él le ha llevado a abandonar su Salé natal para buscar refugio en París. Taye $\varepsilon$ niega que el Islam esté en contra de la homosexualidad y comenta, que "el modo de tratar a los homosexuales en algunos países árabes e islámicos, nos muestra el grado de carencia de una verdadera democracia en ellos. En Marruecos se puede condenar a un homosexual hasta a tres años de prisión. Aunque se ha abierto un diálogo sobre el tema en los últimos cuatro años, la visión de la sociedad sigue siendo muy negativa. Por tanto, los homosexuales no son solo víctimas del poder sino también lo son de las costumbres y tradiciones... Hay voces femeninas que gritan pidiendo libertad, pero siempre chocan con los conservadores que no son islamistas necesariamente, pero sí quieren a hombres y mujeres sumisos y privados hasta de sus intimidades más propias" (9).

Naha Katraji (10) recoge varias obras que tratan de la homosexualidad en los países árabes como: "La desviación sexual en la literatura egipcia” de Mustafa Ba- 


\section{I/: La homosexualidad en el cine árabe}

\section{Monográfico}

yumi, "El placer afortunado, la desviación sexual en la historia de los árabes" de Ibrahim Mahmud (2000), "La desviación sexual en la mujer" Huda Aljarsa (2009), "Amor prohibido, vida de los homosexuales en Oriente Medio" de Brian Whitaker (2009), "Temor a la homosexualidad" editado por la Asociación Holm (Sueño). A nivel de novela encontramos los títulos: "El buey almizclero" de la libanesa Hanan Achaij, "Olor a canela" de la siria SamarYazbik y "Yo soy tu" de la libanesa Ilham Mansur.

En realidad, las novelistas árabes han sido más atrevidas que sus homólogos varones en plantear la homosexualidad en sus escritos. "A excepción de algunos pocos escritores: el libanés Rachid Daif, el marroquí Mohamed Chukri y los egipcios Ibrahim Sunh Allah y Alaa Aswani, la literatura masculina árabe es más conservadora al tratar la homosexualidad que la femenina. Con solo hablar de la homosexualidad en la novela "El edificio Yacoubián" (llevada en 2006 al cine) de Alaa Aswani, el reconocimiento de Suheil Idris en "Recuerdos de amor y literatura" de la homosexualidad de su padre o la afirmación del egipcio Charif Hatata en "Ventanas abiertas" de su violación en la infancia y otras excentricidades, desencadena discusiones y acusaciones que no suceden en la literatura femenina que encuentra más difusión, bienvenida y apoyo", como se comenta en el artículo "La mujer árabe y el sexo" (11).

Pero realmente el impulso y la fuerza que necesitaban los homosexuales para demostrar su existencia y para no ser ignorados y ser tenidos en cuenta, se lo han dado las diferentes asociaciones que, poco a poco, se crearon y fundaron en los diferentes países a partir de 2004. Todas ellas (Holm (Sueño) y Mim (M) en Líbano, Kifkif (Es Igual) en Marruecos, Aswat (Voces) en
Palestina, Abu Nawas (Argelia), Bedayaa (Comienzo) en Egipto, etc.) nacieron con una gran ayuda: una página web.

Internet, como comentamos anteriormente, ha sido de gran apoyo a todos los colectivos de homosexuales por conseguir aglutinar informaciones sobre ellos, por hacer compartir inquietudes y experiencias y, fundamentalmente, por permitir a otras personas ajenas al movimiento acercarse a ellos, informarse para intentar comprenderles y, en definitiva, apoyarles.

Pero nada ha sido tan fácil ni tan sencillo. La creación de estas asociaciones y sus correspondientes páginas Webs de apoyo han sido perseguidas y ultrajadas por los diferentes gobiernos hasta tal punto que el Gobierno egipcio intentó cerrar la Web de los homosexuales egipcios (www.gayegypt.com) en varias ocasiones y no lo ha conseguido por estar, entonces, registrada en Londres.

\section{La Homosexualidad en el cine árabe}

Aunque a nivel mundial se considera que fue Georges Méliès quien primero reflejó la homosexualidad en el cine en 1907 en la cinta titulada "L'Eclipse du soleil en pleine lune", el primer largometraje claramente gay tiene como título "Anders als die Andern" (Diferente a los demás), es de nacionalidad alemana y fue dirigido en 1919, durante la República de Weimar, por Richard Oswald, largometraje cuyo escandaloso estreno fue una de las razones de que en 1920 se reintrodujera la censura en Alemania. En Europa había que esperar hasta 1933 para ver en las pantallas una cinta de temática parecida, siendo el francés Jean Vigo quien con su "Zéro de conduite" pone el dedo en la llaga, teniendo como consecuencia la prohibición 
de la película hasta febrero de 1946 (12).

El cine en los países árabes, como todo lo relacionado con la cultura y con los temas sociales, está y ha estado supeditado esencialmente a los dictámenes religiosos imperantes en cada país y a los gobiernos de turno, que siempre se rigen como los responsables de lo que deben y no deben ver sus conciudadanos. Estos dos factores son y han sido los determinantes para calcular, ante todo, el nivel de libertad del cual se puede disfrutar en el país. Esto nos indica si los ciudadanos gozan de libertad de expresión, de acción, de sindicación, etc. o son seres sometidos a los dictámenes de los dictadores de turno que, disfrazados con uno $u$ otro traje, imponen unas reglas que aunque en algunos casos se han roto con la reciente "primavera árabe" en otros países, siguen imperando.

Pero vayamos por partes. El cine árabe ha tardado en filmar y presentar escenas eróticas y el motivo no es más que la falsa moral tanto de cineastas como de espectadores y administración. Son las reacciones normales en las sociedades oprimidas sexualmente. Resulta que nadie queremos el cine erótico pero todos lo vemos y mejor si es en la intimidad. "El concepto popular de cine erótico parece ser el de cine concebido para poner caliente al personal sin rebasar los límites de lo que la moral cristiana (musulmana) y la legislación de los países consideran pornografía. Pero lo de lo erótico y lo pornográfico es un poco arbitrario; por lo visto en cine consiste más o menos en que si los actores fingen es erótico y si no fingen es pornográfico, mientras que en la literatura, como no se ve, nadie se pone de acuerdo en cuál es la frontera, si es que hay una frontera, entre erotismo y pornografía" (13). Pero no hace falta enseñar nada para enardecer al personal y avivar en él ese deseo tan cohibido. Rita
Hayworth nos lo ha demostrado en "Gilda" (Charles Vidor, 1946), al realizar un striptease en toda regla.

El cine árabe (egipcio) ya en los años cincuenta presentó escenas de desnudos, pero los directores utilizaban la seducción para destacar la belleza de la mujer pero sin enseñar nada de su cuerpo. La actriz Tahia Kariuka en "Chababo imrahaa" (Juventud de una mujer) ha logrado seducir a un joven campesino sin enseñar su cuerpo y lo mismo sucedió con la actriz Huda Sultan en "Imraa ala attarik" (Una mujer en el camino) de Azeddin Du Alfakar (1958), y lo mismo pasó con las actrices Hind Rustum, Chadia y Fatin Hamama que utilizaron la seducción insinuando y no por medio de imágenes calientes (14). En los años sesenta y setenta han presentado infinidad de escenas llenas de erotismo. Películas banales sin contenido ni tema que contar. Galanes, jóvenes muy guapas, bailarinas de cabarets y mucho glamur, mezclado con un poco de violencia, sadismo y hasta con ciertas dosis de drama.

La temática del cine árabe no es difícil de adivinar. Chica quiere a chico, chico quiere a chica. Uno de los dos es rico y el otro es pobre pero la familia, en ambos casos, se niega a que se celebre el matrimonio. Películas como "Zarzara fauka Nil" (Charlas sobre el Nilo) de Hussein Kamal (1971) basada en la novela de Najib Mahfud donde un grupo de amigos, políticos e intelectuales, se reunían en un barco anclado en el Nilo para divertirse mezclando sexo, baile, drogas y alcohol; "Abi fauka achajara" (Mi padre en el árbol) también de Kamal donde se enfrascan Abdelhalim Hafid y Nadia Lotfi en un mar de besos, al igual que Mahmud Yasin y Mirfat Amin en "Anf wa zalazat ouyun" (Una nariz y tres ojos). Y vuelve Hussein Kamal para escenificar la obra del gran Ihsan Abdelkaddus 


\section{I/: La homosexualidad en el cine árabe}

"Dami, dumuhi wa ibtisamati" (Mi sangre, mis lágrimas y mi sonrisa) donde el matrimonio de Nahid es una tapadera para cubrir su relación de pecado con un pudiente hombre de negocios. Y la lista es más larga todavía: "Tuyur addalam" (Los pájaros de la oscuridad", "Arrajulo azzalez" (El tercer hombre), "Indar bi attaa" (Aviso para obedecer", "Aluan assamah assabaa" (Los siete colores del cielo), "Imraa wa jamsato rijal" (una mujer y cinco hombres), "Zankato assittat" (Calle de las señoritas),"Imnaa wahida takfi" (Con una mujer basta), "Al katila" (La asesina) con interpretaciones de Yusra, Laila Alawi y la bailarina Fifi Abdou. El mismo caso se aplica a los actores que han tenido que intervenir con desnudos parciales o totales y sobre todo Adil Imam en "Assifara fi al imara" (La embajada en el inmueble), "El inmueble Yacubian" al que nos referiremos más tarde por estar incluido entre las películas que tratan la homosexualidad y "Attajriba addanimarkia" (La experiencia danesa) donde se muestra cómo practicar sexo y donde aparecen los egipcios como pueblo sediento de sexo (15).

En los años ochenta del pasado siglo se endurece la censura en Egipto y se llevan a cabo varios juicios dentro de una maniobra de enjuiciamiento contra las películas que incluían desnudos y sensualidad producidas entonces. El primero fue contra "Lilhob kisat ajira" (El amor tiene una historia final) de Raafat Almihi cuyos actores Yahya Alfajrani y Maali Zaid fueron juzgados por practicar lo prohibido a la vista, siendo la actriz condenada a tres años de prisión, y del mismo modo han sido censurada la película "Khamsat bab" (La quinta puerta) protagonizada por Nadia Aljondi y "Darb al hawa" (El callejón del amor) donde intervienen Yusra, Madiha Kamel y Ahmed Zaki (16). En todo caso, entre los países árabes y sobre todo en el
Egipto de esta época, se podía hacer cine con contenido erótico pero nunca cine social que critique la religión, la política, la situación de los derechos humanos y de la libertad de expresión.

En los años noventa se inicia la producción de pequeñas comedias sociales coincidiendo con la negación de varias actrices en participar en películas de desnudos, destape e insinuaciones sexuales, naciendo la plataforma "Assinima annadifa" (El cine limpio) que condena la aparición de la mujer en escenas más que sospechosas.

\section{La homosexualidad}

El escritor y fotógrafo francés Frédéric Lagrange comenta que el primer personaje homosexual que aparece nítido en una novela árabe contemporánea es el personaje de "Charka" en la texto de Najib Mahfud "Zukako al madak" (El callejón de los milagros) publicado en El Cairo en 1947 (17). Las primeras imágenes aparecidas tanto en las salas de cine como en las pantallas de la televisión de los países árabes, han presentado a la homosexualidad en plan cómico. Jóvenes varones que vestidos extravagantemente o con ropa femenina, aparecían repitiendo ademanes, gestos y movimientos muy sospechosos y afeminados, que sólo buscaban arrancar una sonrisa del espectador tanto masculino como femenino (18). Ningún director ni productor se atrevía a plantear el tema en abierto como han presentado en sus películas imágenes de desnudos, besos y hasta fuertes escenas eróticas en el pasado. Además la censura ejercida entonces en los medios era atroz. Nadie se sentía capaz de abordar una relación tabú, condenada y castigada por las leyes imperantes en casi todos los países del entorno. A lo 
sumo los directores se permitían lanzar pequeñas insinuaciones que podrían llevar a las "imaginaciones más extravagantes" a hacer cábalas y a ver cosas raras donde los demás dirían que no hay nada.

Se parte ante todo de la idea de que, en general, los organismos de censura en los diferentes países nunca han admitido las escenas de amor, ni los desnudos aunque fueran parciales, ni tampoco los besos en ninguna imagen aunque fuera en las películas extranjeras importadas. Por lo tanto se puede afirmar que pocas películas trataron el tema de la homosexualidad a excepción de una cinta del prolífero egipcio Fatin Abdelwahab que en 1954 desafió a todo el mundo en “Anisa Hanafi” (La señorita Hanafi).

La homosexualidad siempre ha sido vista desde un modo negativo. Envuelta de infinidad de precauciones o disfrazada disimuladamente con el humor. Los personajes hacen pero no dicen el qué ni el cómo ni el cuándo. Interpretan, actúan, seducen, enseñan pero en silencio y sin hablar del tema. Está permitido hacer pero no hablar de ello. Por otro lado, se cree que presentar la homosexualidad o hablar de ella, resta calidad artística, cultural e intelectual a la película.

Se piensa, por el contrario, que los jóvenes cineastas árabes, que estudiaron y aprendieron el oficio en Europa y América y se han nutrido de su cultura y sus vivencias, iban a ser valientes y atrevidos a la hora de plantear temas que podrían herir la sensibilidad de los espectadores y que no tendrían ningún tabú ni impedimento que les podría cohibir ni coartar.

Desde siempre el tema de la homosexualidad ha tenido más detractores que defensores. El crítico marroquí Ahmed Sejelmassi opina que "la presencia de la sexualidad en el cine marroquí es una cosa normal porque el sexo forma parte de la vida del hombre. Y si el arte en general y particularmente el cine está relacionado con el hombre en sus diferentes vertientes, pues uno no puede imaginarse al cine sin sexo. Pero esta presencia es diferente en cada película, ya que hay films con escenas sexuales gratuitas que no favorecen la construcción dramática tanto como la turban, ya que son introducidas de modo arbitrario por el director. Por el contrario encontramos films que tratan temas sexuales sospechosos tratados de un modo artístico y atrevido con insinuaciones y permisibilidad, en contra de las escenas calientes que dramáticamente no tienen excusa" (19).

El profesor de chariaa islámica de la Universidad Al Azhar de El Cairo ha declarado que "presentar escenas de sexo y homosexualidad en las pantallas de cine y TV es un pecado, lo mismo que su visionado y ha afirmado que la homosexualidad no existe en Egipto" (20).

En nuestra búsqueda hemos encontrado 51 películas árabes que tratan la homosexualidad desde muchas vertientes. Evidentemente estas no son todas las que son, pero sí son todas las que están. En la lista adjunta se recogen todas estas películas clasificadas por su año de producción. El problema no es solo el no haber encontrado el año de producción de la mitad de ellas sino, en muchos casos, el no saber nada de su director ni de su productor, por haberla encontrado tan solo citada en un documento o artículo.

Lógicamente la mayoría de estas películas son de nacionalidad egipcia (31 exactamente) $(60,78 \%)$, cinco son marroquíes, cuatro libanesas, dos tunecinas y otras dos argelinas, correspondiendo una película a Palestina, Francia, Reino Unido, Estados Unidos y hay tres coproducciones (Egipto-Argelia, TúnezMarruecos y Bélgica- Francia). Por lo que se puede 


\section{I/: La homosexualidad en el cine árabe}

\section{Monográfico}

ver, aquí faltan muchos países árabes y la razón no es otra que la férrea censura existente que sus países. A excepción de alguna rareza que nos podríamos encontrar, es a partir de los años setenta que el cine árabe se interesa por la homosexualidad, no siendo motivo de rareza que la primera cinta clasificada sea del egipcio Youssef Chahin (del cual incluso se decía que era gay) que siempre ha hecho guiños al tema como veremos más adelante.

Pasamos a analizar las películas donde se trata el tema de la homosexualidad, habiendo tenido algunas de ellas una gran difusión, después de ser motivo de grandes disturbios y protestas por los no conformes con sus estrenos, después de haber pasado duros controles de las juntas de control y censura en los países correspondientes, teniendo en cuenta que tan solo dos de estas películas están dirigidas por una mujer, la libanesa Joseline Saab y la egipcia Innas Daguidi.

Para aglomerarlas hemos utilizado varios criterios: las que tratan la homosexualidad masculina, la femenina, las de un director determinado, por países o por cualquier otro concepto que nos permita estudiarlas y analizarlas, siempre teniendo en cuenta que en ciertos casos no tenemos ningún dato sobre ellas.

\section{Documentales}

Todas las películas son de ficción exceptuando tres documentales, el estadounidense "A Jihad for love" (Jihad por amor), la británica "I am gay" realizado por Abdul Rahman El Shayal que incluimos aquí por estar realizados por jóvenes de origen árabe y "How I lavé you" (Como yo te amo) del libanés Akram Zaatari. En el caso del primero fue realizado en 2007 y trata de la "convivencia entre el Islam y la homosexuali- dad y presenta la lucha interna del homosexual entre su deseo y sus creencias religiosas que lo prohíben”, según cuenta Ahmed Jairi Omari (21). El documental ha sido grabado en varios países árabes y para el director "es una lucha entre el deseo homosexual y la tradición, las explicaciones que se dan del Corán y se afirma que el Islam no prohíbe la homosexualidad y el homosexual debe ser creyente, adepto a su religión hasta el punto de utilizar la "jihad" y luchar por su amor hacia su compañero (22).

«"I am gay" (Yo soy gay) fue dirigido para la BBC sección Árabe en 2010 Abdurahman Shayal. "Este es el primer documental realizado por un canal de televisión árabe sobre la homosexualidad en el mundo árabe, "I am gay" aborda este problema de frente, dando voz a los jóvenes gays en cinco países. Desde Marrakech, una ciudad tolerante, a Egipto con las redadas policiales y los juicios públicos, hasta Tel Aviv» (23).

"How I love you" (Como yo te amo), dirigida en 2001 por el libanés Akram Zaatari. "Es un buceo en la sexualidad de hombres gays del Líbano. Cinco personajes hablan sobre su vida sexual, sus compromisos, su relación con el cuerpo y sus pasiones y amores en una sociedad que aún pone la homosexualidad con la detención. La luz del vídeo produce un velo blanco que tolda la visión, de modo que tornase casi imposible la identificación de los personajes" (24).

Homosexualidad masculina

- "Hammam Al Malatily" (El baño Al Malatily) dirigida por el también egipcio Salah Abu Saif.

$\mathrm{Y}$ "aunque el cine egipcio, desde su creación, ha presentado muchos personajes homosexuales, la mayoría de estos dispositivos han sido cómico insertado para 
generar una cuantas risas baratas. Las representaciones de la homosexualidad sólo graves han sido a través de un personajes de poca importancia en un puñado de películas egipcias como Salah Abou Seif "La Casa de Baños de Malatily” (1973), “Alejandría... ¿Por qué? de Youssef Chahin" (1978), "Beggars and Proude Ones" (Los mendigos y los orgullosos) (1991) de Asmaa Bakry, "Marcides" de Yousry Nasrallah (1993) y "El edificio Yacobián" (2007) de Marwan Hamed. Sin embargo, estos se presentaron de una manera tan sutil, sólo insinuado, para ser detectado por los iniciados (25). Las secuencias de la película se llevan a cabo en un baño árabe popular y las imágenes están muy subidas de tono hasta el límite que la protagonista Chams Al Barudi intenta cada vez, desde su jubilación, que se retire la película de las salas sin conseguirlo ya que es visto todavía por miles de jóvenes (26).

- "Le harem de madame Osmane" (1999) del argelino Nadir Mokneche. "El director de esta película se sumerge en un mundo casi exclusivamente femenino, cuya figura central, Madame Osmane, reina sobre un microcosmos de los individuos en los que la ley es la de los hombres. Una figura sobresale, un solo hombre es admitido a las fiestas que reúnen a las mujeres antes de un matrimonio: su peluquero homosexual todo de blanco, interpretado por el joven actor Atmen Khélif" (27).

- "Tarik el hob" (Camino del amor), producción francesa de Rémi Lange (2003).

"Karim, dice que es heterosexual y es estudiante de sociología, tiene por objeto, entre los jóvenes de origen norteafricano, gays dispuestos a testificar en su pequeña cámara. Se encuentra con Farid, un chico desinhibido, que está dispuesto a responder a las preguntas y tal vez a más. El comportamiento de Karim parece paradójico: vive con su novia y el aprendizaje junto a su nuevo amigo" (28). Ganadora del premio a la Mejor Película de 2003 de Lesbians Seattles y el Festival de Cine Gay y Mención de Honor en Nueva York y Lesbiana Festival de Cine Gay.

- "Imarat Yacoubian" (Edificio Yacoubian), Egipto 2006, dirigida por Marwan Hamad. "Más de cien parlamentarios quieren censurar las escenas homosexuales de una cinta que está rompiendo todos los records del cine egipcio y que trata numerosos asuntos tabúes o delicados como la tortura, el aborto, la corrupción y la homosexualidad. La iniciativa ha partido de 112 parlamentarios que han pedido un visionado en el mismo hemiciclo de la película para cortar al menos las escenas más escandalosas, que son las que muestran a un respetado periodista homosexual en su relación con un soldado" (29). La película ganó un premio en el Festival Tribeca de Nueva York.

- "Le fil" (El hilo) (2008): Largometraje belga-francés realizado en Túnez por Mehdi Ben Attia en el cual interviene la legendaria Claudia Cardinale en el papel de la madre del protagonista. "Malik es un arquitecto de una buena familia en Túnez. Cuando salió de Francia para regresar a casa, sólo piensa en una cosa a revelar a su madre que le gustan los chicos. Y luego, casi a primera vista, que se enamora de Bilal, un hombre joven a su madre emplea para algunos servicios... Con Archivo, actor y escritor tunecino Mehdi Ben Attia logra su primer largometraje como director. Si evoca temas específicos de gays y lesbianas, como el amor y el deseo escondido de los niños, la película no pretende ser sociológica. Por el contrario, trata de demostrar que la homosexualidad es un tabú, aunque en realidad no sea un problema” (30). La actriz Ramla Ayyari, que interpreta un papel de lesbiana en el film, 


\section{I/: La homosexualidad en el cine árabe}

\section{Monográfico}

ha sido duramente criticada por parte de la prensa árabe a lo que ella respondió que solo se trataba de presentar a un personaje como cualquiera de los que ha presentado, y que nada tiene que ver personalmente con ella. Y añade que "lo que más me ha dolido es la manera con la que algunos plumillas han tratado el tema y se han erigido en doctos de la religión y han discutido su trascendencia religiosa y política" (31).

- "Help", dirigido en 2008 por Marc Ali Rached. "Es una película libanesa que cuenta la historia de Ali, un adolescente que vive en una furgoneta y ve su vida trastornada a partir del encuentro con Thuraya, una prostituta que vive con un homosexual" (32). El film había recibido la autorización de exhibición con dos condiciones: quitar una escena de sexo y estar prohibido para menores de 18 años. Pero tres días antes del estreno le fue retirada la autorización de exhibición. Se cree que es porque la actriz principal Joanna Andraos, hija de un diputado libanés, sale completamente desnuda en la película.

- "Tul omri” (Toda mi vida), dirigido en 2008 por el egipcio Maher Sabri, presidente de la Asociación Egipcia de Cine Marginal. Hace referencia a la vida de los homosexuales, a los problemas a que se enfrentan, sobre todo después de la persecución a que son sometidos tras la condena de cinco homosexuales a tres años de cárcel y tres de residencia vigiada por libertinaje en abril de 2008 (33). El film cuenta la historia del joven Rami que sufre síquicamente tras ser abandonado por su querido Walid para casarse con su amiga Dalia. La película incluye por primera vez una escena de verdadero sexo entre los participantes (34). - "Al Irhab wa al kabab" (Terrorismo y aflicción), una de las cientos de películas protagonizadas por el actor egipcio Adel Imam donde, como ciudadano "busca a un funcionario para tramitar unos documentos de su hijo y le comentan que se encontraba en los servicios de un hotel cercano donde acude rápidamente y llama a las puertas de las cabinas preguntando por Madhat hasta que le sale un joven homosexual que le contesta Si quieres que sea Madhat seré Madhat por lo cual este nombre permanece como un símbolo para los gays egipcios" (35).

\section{Homosexualidad femenina}

De entre las películas que tratan el lesbianismo encontramos:

- "Bidune rikabat"(Sin control): Dirigido por el egipcio Hani Jarjes Fauzi, trata la homosexualidad femenina a través de la vida alegre y sin preocupaciones de un grupo de jóvenes, sin control alguno por parte de sus padres. La cinta tuvo problemas con la censura por solicitar que se elimine una escena protagonizada por la joven Alaa Ganem y por unos diálogos calificados de atrevidos (36).

- "Kalimato sir" (Palabra secreta): Ha sido una de las once películas a las cuales el Comité de Censura egipcio negó calificar por tratar la homosexualidad femenina (37).

- "Alakat sajina" (Relaciones calientes): Dirigida por el palestino Muhnis Chawarbaji, la película presenta una relación de lesbianismo entre dos jóvenes. El director declara en una entrevista que las imágenes de la película son sensuales y seductoras. Se basan más en la seducción: la mirada que dirige una de las protagonistas a su compañera durante el baño, la manera de tocarse cuando las une el mismo lecho,... El director afirmó que la censura no iba a prohibir la película porque las jóvenes no aparecen desnudas y su 
relación se produce de manera fortuita cuando cada una de ellas tiene una relación de amor normal con un hombre (38).

- "Hina Maysara", cinta egipcia que ha sufrido la crítica de la prensa y de la sociedad civil egipcia al igual que "El edificio Yacoubian", dirigida en 2007 por Jalid Youssef. Trata el lesbianismo entre dos mujeres: Nahid (Gada Abderrazak) que se enamora locamente de Sumaya Khachab, una guapa y exuberante mujer de los suburbios que vuelve locos a los hombres" (39).

- "Ma tigui narkas" (Ven y bailamos): Dirigido en 2007 por la cineasta Innas Daguidi quien en 2008 pidió la legalización de los burdeles en Egipto por ser una cosa real del cual no tenemos escapatoria al mismo tiempo que negaba su condición de lesbiana diciendo que "soy casada y madre y he vivido una historia de amor que conoce todo el mundo artístico" (40). Daguidi criticó al hombre oriental diciendo que solo mira de cintura para abajo, ha negado publicitar la homosexualidad en su película donde dice que sólo presentó modelos diferentes de la realidad tal como corresponde al cine.

\section{Youssef Chahin}

El genial Chahin ha sido siempre el más atrevido de los cineastas egipcios. Ha tenido varios encontronazos con la censura, ha hecho varios guiños a la homosexualidad, sus películas están en la cabecera de las películas clasificadas con un " $\mathrm{X}$ " $\mathrm{y}$ ha dirigido las más legendarias películas de la historia cinematográfica del mundo árabe ("La Tierra") y "Al Osfour" (El gorrión).

- “Annil wa nasu" (La gente y el Nilo): La película que se produce en 1968 y no se exhibe hasta 1972 hace referencia a "la construcción de la presa de Asuán, cómo se ha visto por aquellos que tomaron parte en ella: los ingenieros y los trabajadores, los egipcios y los soviéticos. A partir de un día, las aguas del Nilo fueron desviadas, y Chahin muestra cómo las preocupaciones individuales a veces superan el mito que rodea una empresa colectiva". "El espíritu con que fue dirigida la llevó a su prohibición. En realidad, la versión exhibida en 1972 fue un nuevo montaje de la película; pero hubo que esperar veinte años para poder verla en su versión original en Francia, en 1992, con el título" "El Nilo y la vida" (41).

- “Iskandaria,... ¿lih?” (Alejandría... ¿Por qué?): La película 29 del legendario Youssef Chahin y primera de la saga de films autobiográficos realizados sobre su ciudad natal Alejandría. "En 1942, con el mariscal Rommel a las puertas de Alejandría, la ciudad está en plena ebullición y la población reacciona de las formas más diversas. Mientras que algunos se regocijan con el anuncio de la victoria alemana, otros, como la familia de Sorel, de confesión judía, hacen las maletas y obligan a su hija a abandonar al sindicalista musulmán Ibrahim, del cual la joven espera un hijo. En el centro de toda esta agitación se encuentra el joven Yehia, que aprovecha los acontecimientos para satisfacer su deseo de dirigir y organizar algunos espectáculos, con una sátira bastante corrosiva de todos los frentes. Al final, Alejandría no será invadida y Yehia hará realidad su mayor sueño: viajar a los Estados Unidos para estudiar cine" (42). Por otro lado el tío del protagonista se enamora de un soldado británico, relación secreta que se descubre en una escena donde el soldado despierta al tío estando en ropa interior. En realidad el cineasta evoca abiertamente una aventura homosexual entre un egipcio y un soldado británico y 


\section{I/: La homosexualidad en el cine árabe}

\section{Monográfico}

peor aún, se atreve en paralelo presentar una historia de amor entre un musulmán y una chica judía (43). - “Al Iskandaria kaman wa kaman" (Alejandría de nuevo y siempre" realizada en 1989, donde el héroe del film (supuestamente el propio cineasta) se enamora de un joven pero la relación no se hace patente más que en una escena a través de una canción y de un baile (44).

\section{Marruecos}

Siempre ha sido el país más moderado dentro del área árabe. Produce bebidas alcohólicas que se venden y consumen en el país y es tolerante con la homosexualidad, el destape y nada estricto en plan religioso. $\mathrm{Su}$ cine es abierto y poco censurado. Entre las películas que encontradas dos están dirigidas por Nabil Ayouch, dos por Daoud Oulad Sayad y una por Nouredin Lakmari.

- "Kulo ma turidoho Lola" (Todo lo que Lola quiere): Cinta marroquí con financiación franco-canadiense dirigida en 2007 por Nabyl Ayouch. "Banda original del film "Soundtrack Whatever Lola Wants" de Nabil Ayouch, con Carmen Lebbos del Líbano, Laura Ramsey de los Estados Unidos, Assaad Bouab de Marruecos. Lola, de 25 años, vive en Nueva York, trabaja para hacer realidad su sueño de bailarina. Youssef, su mejor amigo es un joven gay egipcio que vive su vida en Nueva York. A través de él, de Lola descubre la historia Ismahan, estrella de la danza oriental, una leyenda de El Cairo. En el restaurante donde trabaja Youssef, Lola conoce a otro egipcio, Zack. El romance acaba rápidamente cuando Zack se da cuenta de las diferencias culturales que los separan y regresó a Egipto. Sin pensarlo, Lola, tan ingenua como impulsiva, inmediatamente decide seguirlo, frente a un Youssef aterrorizado. Cuando llega a El Cairo, queda decepcionado por la recepción de la familia de Zack, así como por la actitud del joven, Lola sale en busca de la fascinante bailarina Ismahan" (45). http://blog. enarm.org/tag/wants/

- "En attendant Pasolini” dirigido en 2007 por Daoud Oulad Sayad, el film ha obtenido el Premio al Mejor film árabe en la 31 edición del Festival Internacional del Film de El Cairo. El film "cuenta la historia de Thami, quien trabajó como extra en películas extranjeras en su pueblo cerca de Ouarzazate. Se convirtió en un amigo del director italiano Pier Paolo Pasolini durante el rodaje de su película "Oedipe Roi" en 1966" (46).

- “Adieu Forain”, dirigdo en 1998 por Daoud Aulad Aayad. "Tres destinos se entrecruzan y chocan en la primera película del director marroquí Daoud Oulad Sayad. Kacem, quien es dueño de un stand de lotería stand de una calle, en gage Rabii, un joven bailarín travestí y Larbi, su hijo, que trabaja con su padre sin saber su verdadera identidad" (47).

- "Une minute de soleil en moins" (Un minuto de sol por lo menos), dirigida en 2002 por Nabil Ayouch. "Este thriller se atreve a cuestionar la identidad sexual, el marroquí Nabil Ayouch viola muchos tabú, hasta el punto de ser satanizado por sus compatriotas. Hay que decir que la imagen de la policía que presente el cineasta no es compatible con las normas de la sociedad marroquí: Kamel, tiene por su mejor amigo a un travestido que se enamora de una mujer, Toria, que actúa como hombre. La película pone de relieve algunas cuestiones básicas acerca de la sexualidad, que desafía la hipocresía de una sociedad silenciada" (48). - "Casanegra" dirigida en 2008 por Nouredin Lakmari. "Casanegra", es el segundo largometraje del director Lakhmari Noureddine, de 44 años, que se está 
convirtiendo en un fenómeno social en Marruecos. En las cuatro ciudades - Casablanca, Rabat, Tánger y Marrakech - donde la película se proyectó el 24 de diciembre de 2008, las salas suelen estar llenos. Las mujeres jóvenes, viejos, ricos, pobres, o mujeres con velo o en jeans, acuden en masa. La historia presenta a dos jóvenes desempleados, de unos veinte años, que viven de pequeños trucos y con el sueño de Europa, el dinero y el sexo. Pero el personaje principal de la película es Casablanca. Casanegra juega con la Casablanca y revela ambientes turbios, especialmente en la noche. Una ciudad dura y peligrosa, que lleva a la desesperación. Éstos están excluidos de la bonanza económica anunciada por las élites. Se trata de la ira, agresiones físicas y verbales de los que defienden sus territorios. El lenguaje es Darija, el dialecto árabe marroquí, pero en su versión más popular" (49).

Otras películas

- "Kitato ala nar" (Gata sobre tejado caliente), basada en la obra de teatral de Tennessee Williams donde el actor principal Nour Acharif se acompaña de un amigo "pervertido" y "Jarta al ouohuch" (Carrera de salvajes) que fueron interpretadas por Nour Acharif. "Titu" de Ahmed Sekka que trata la homosexualidad desde la vertiente más dura al decidir un preso matar a otro por agredirle sexualmente ya que consideró que el castigo por semejante agresión era la muerte; "Attarik" (El camino), película producida en los años sesenta y en la cual participa la exuberante Fatin Hamama; "Assuud ila alhawiya" (Subida al abismo) que dirige en los años setenta Kamal Achaij, donde la actriz Madiha Kamel representa a una espía que trabaja para el enemigo israelí y a quien se deshonra y pervierte (50) por afiliar a mujeres mediante la relación que mantiene con ellas. "Yana ya jalti" (Yo, tía), diri- gida por Saeed Hamed y protagonizada por Mohamed Hindi, Hassan Hosni, Donia Ghanim; "Racha jariaa" (Rociadura atrevida) dirigida por el egipcio Achraf Abdelbaki donde el protagonista quiere ser actor y para conseguirlo debería acostarse con el director; "Rih assad" (Viento de la presa) dirigida por el tunecino Nouri Biuzid; "Ali” del libanés Bajus Alwan; "Suk al mutaa" (Mercado del placer) dirigida por el egipcio Walid Hamad; "Arrakisa wa asiwasi" (La bailarina y el político) con la interpretación de Faruk Fluks que acompaña siempre a la bailarina Nabila Abid quien comentó que le pondría su nombre a un orfanato aunque fuera homosexual ya que las autoridades no le dejaban poner el suyo por ser bailarina (51).

- "Tul omri" (Toda mi vida): Dirigida por el egipcio Maher Sabri, el film se basa en la detención de uno grupo de "pervertidos" en lo que se ha llamado el caso del barco Qeen But en 2004 (52).

- "Dunia", de la libanesa Joseline Saab, fue presentado el Festival Cinematográfico de Cartago, Túnez en 2006. El tema del film es la relación de los árabes con el cuerpo a través de la relación de tres mujeres con sus esposos y la influencia de la esterilización femenina, tan extendido en Egipto, en la relación sexual entre el hombre y la mujer y el sufrimiento de la mujer por esta operación.

- "Marcides", película egipcia escrita y dirigida en 1993 por Yousry Nasrallah. "Noubi, un comunista declarado de una familia rica, intenta encontrar a su hermanastro Gamal después de que éste heredara la fortuna de su padre. Noubi, como se supone, mata a su madrastra Raifa, presunta traficante de droga, antes de que ella matara a Gamal" (53).

Y por último incluimos las cintas sobre la que no tenemos más datos que sus títulos: "Sayeh bahr" (Dis- 


\section{I/: La homosexualidad en el cine árabe}

\section{Monográfico}

persar el mar) donde un joven "pervertido" aparece acompañando un hombre de negocios, "Bint ismoha Mahmud" (Una chica llamada Mahmud), "Kachf al mastur" (Descubrir lo oculto), "Rasailo al bahr" (Cartas marinas).

\section{Vestir con ropas del sexo contrario}

Películas donde hombres y mujeres que, por algún modo u otro, se visten con ropas del sexo contrario como "Anisa Hanafi" (La señorita Hanafi) dirigido en 1954 por Fatin Abdel Wahab en la que el humorista Ismael Yassin aparece vestido de novio en la primera parte y de novia en la segunda en una total contradicción y tirándole los tejos a un forzudo, acompañado con una música rítmica popular con la sugestiva bailarina Soraya Salem moviendo la cadera y los pechos y enseñando sus muslos y largas piernas (54), en "Lirijale fakat" (Solo para los hombres) donde las actrices Suad Hosni y Nadia Lotfi se visten de hombres y "Sukar hanim" (La señora Sukar) que es una parodia teatral y televisiva egipcia que en cine protagonizó Abdelmonhem Ibrahim que aparece también vestido con ropa de mujer.

\section{Notas}

1. Tawfik, Saad Eddin; "Kissat assinima fi misr" (Historia del cine en Egipto), Dar Al Hilal, No 221, agosto 1969 , pág. 9 .

2.http://fr.wikipedia.org/wiki/ homosexualit\%C3\%A9_dans_líslam

3. El Corán, Traducción, introducción y notas de Juan Vernet, Círculo de Lectores, Barcelona 2002: 134.

4. Ibídem, 2002: 333.
5. http://sex.rewech.com/show.php?id=1669

6. http://www.islaternura.com/APLAYA/NoEresElUnico/aLETRA/Ab/Abu\%20Nuwas/ \%20POEMAS.htm

7.http://fr.wikipedia.org/wiki/ homosexualit\%C3\%A9_dans_líslam

8. http://sex.rewech.com/show.php?id=1669

$9 \mathrm{http}: / /$ www.almolahed.info/index.php?option=com content $\&$ view $=$ article $\&$ id $=466: 2009-07-16-11-31$ $35 \&$ catid $=50$ marsad $\&$ Itemid $=56$

10. Naha Kartagi en: http://sex.rewech.com/show. php?id=1669

11. http://arb3.maktoob.com/vb/arb182586/

12.http://es.wikipedia.org/wiki/Z\%C3\%A9ro_de_ conduite

13. http://www.pasadizo.com/index.

php?option $=$ com_content $\&$ view $=$ article $\& i d=1039$

14. http://www.alrankosi.net/vb/archive/index.

php/t-16749.html

15. Daah Hassan en http://www.alfanonline.com/ show_files.aspx?fid=145824

16. Ibídem.

17. http://alrafidayn.com/2009-05-26-22-2136/31665-2011-03-28-04-33-56.html

18. Películas como “Anisa Hanafi” (La señorita Hanafi) y "Sukar hanim" (La Sra. Sukar) donde aparecen Ismael Yassin y Abdelmonhem Ibrahim con vestimenta femenina, además de "Lirijale fakat" (Solo para hombres) donde las actrices Suaad Hosni y Nadia Lotfi se visten con ropa masculina.

19. Mustafa Ben Abdelmalek en: http://www. maghress.com/attajdid/46670

20. http://www.dai3tna.com/nuke/modules.php?na me $=$ News \& file $=$ article $\&$ sid $=7199$

21. y 22. http://ar.wikipedia.org/wiki/ 


\section{II: Homosexualidad e Imagen}

23. http://merhabablogspot.com/2010/11/merhabacinemadebat-festival-cinema.html

24. http://www.artealameda.bellasartes.gob.mx/Archivo/images/7/7f/Hojadesala-despazamientos.pdf 25. http://www.maraiafilm.com/eufs/prelease.html 26. http://www.alrankosi.net/vb/archive/index. php/t-16749.hyml

27. www.aflam.fr/spip.php?rubrique 45

28. http://wwwwww.sensacine.com/peliculas-40517

29. http://dunyaasociacion.spaces.live.com/Blog/ cns!D41D283CCB562F3!1144.entry

30. http://www.jeuneafrique.com/Article/ ARTJAWEB20100514150023/cinema-tunisie-homosexualite-realisateurmehdi-be-attiail-est-plus-subversif-de-montrer-le-bonheur-dans-1homosexualite-que-de-montrer-l-entrave.html 31. http://www.gerasanews.com/web/print. php?a=30899

32. http://observers.france24.com/ar/ content/20090424-naked-woman-banned-lebanesecinema-help

33. http://www.conocereisdeverdad.org/wibsite/ index.php.id $=4570$

34. http://www.ibb7.comnews578.html

35. http://www.za77eef.com/vb/showthread. $\mathrm{php} ? \mathrm{p}=2945$

36. http://forum.kuwaitup.com/t283582.html

37. http://www.soptimes.com/index.

php? mode $=\mathrm{t} \& \mathrm{t}=1372$

38. http://www.ensan.net/news/126/ARTI-

CLE/2482/2008-03-17.html

39. http://www.alraynews.com/News.aspx id $=64053$
40. http://www.algamal.net/articles/details.

aspx? $\mathrm{id}=3462$

41. http://www.library.cornell.edu/colldev/mideast/ chahine.htm y

http:/www.revistasculturales.com/articulos/38/

intramuros/947/1/youssef-chahine-el-gran-cineastaegipcio.html

42. http://aldadis.com/aldadis/secciones/thenews/499-ciclo-de-youssef-chahine-en-lima.html 43. http://cinemasumer.blogspot.com/2008/04/blogpost 08. html

44. http://www.hamasna.com/also.html

45. http://blog.enarm.org/tag/wants/

46. http://www.blabi.net/en-attendant-pasolinifestival-caire.html

47. http://www.critikat.com/adieu-Forain.html

48. http://www.babrio.com/une-minute-de-soleil-enmoins-nabil-ayouch-2002-arabe-sous-titre-fr, 1704.

html

49. http://www.goovideo.com/?2009/02/10/1335casanegra-film-verite-sur-casablanca

50. http://kenanaonline.com/users/Cinema/topics/72843/spots/148220

51. http://www.dai3tna.com/nuke/modules.php?nam $\mathrm{e}=$ News\&file $=$ article $\&$ sid $=7199$

52. http://www.palmoon.net/2/topic-121-147.html

53. http://www.imdb.com/title/tt0107514/plotsummary

54. http://webjournal.us/54971/dance-scenesfrom-al-anisa-hanafi-1-(soraya-salem-and-na-metmokhtar)/ 